\title{
Forced international migration for refugee food: a scoping review
}

\author{
Migração internacional forçada e alimentação de refugiados: \\ uma scoping review
}

Juliana Vidal Vieira Guerra (https://orcid.org/0000-0002-4509-1343) ${ }^{1}$

Valdecyr Herdy Alves (https://orcid.org/0000-0001-8671-5063) ${ }^{2}$

Lilyane Rachedi (https://orcid.org/0000-0001-9024-9819) ${ }^{3}$

Audrey Vidal Pereira (https://orcid.org/0000-0002-6570-9016) ${ }^{2}$

Maria Bertilla L. Riker Branco (https://orcid.org/0000-0002-5117-644X) ${ }^{1}$

Márcia Vieira dos Santos (https://orcid.org/0000-0002-1488-7314) ${ }^{1}$

Mariana Cabral Schveitzer (https://orcid.org/0000-0001-9833-2932) ${ }^{4}$

Bruna Fernandes Carvalho (https://orcid.org/0000-0002-4282-5540) ${ }^{2}$

${ }^{1}$ Programa Acadêmico em Ciências do Cuidado em Saúde da Escola de

Enfermagem Aurora Afonso

Costa, Universidade Federal

Fluminense. R. Dr. Celestino

$74,6^{\circ}$ andar. $24020-$

091 Niterói RJ Brasil.

julianaguerra.personaldiet@

gmail.com

${ }^{2}$ Escola de Enfermagem Aurora de Afonso Costa

Universidade Federal

Fluminense. Niterói RJ

Brasil.

${ }^{3}$ Escola de Serviço Social,

l'Université du Québec

à Montréal. Centre Ville

Quèbec Montréal Canada.

${ }^{4}$ Escola Paulista de

Medicina, Universidade

Federal de São Paulo. São

Paulo SP Brasil.

\begin{abstract}
Recent crisis and conflicts in African countries, the Middle East and the Americas have led to forced population migration and rekindled concern about food security. This article aims to map in the scientific literature the implications of forced migration on food and nutrition of refugees. Scoping Review, and database search: databases: PubMed Central, LILACS, SciElo, Science Direct and MEDLINE. Languages used in the survey were: English, Portuguese and Spanish, with publication year from 2013 to 2018.173 articles were obtained and after removing of duplicates and full reading, 26 articles were selected and submitted to critical reading by two reviewers, resulting in 18 articles selected. From the analysis of the resulting articles, the following categories emerged: Food Inequity; Cultural Adaptation and Nutrition; Emerging Diseases and Strategies for the Promotion of Nutritional Health. Food insecurity is a marked consequence of forced international migration, and constitutes an emerging global public health problem, since concomitant with increasing population displacements also widens the range of chronic and nutritional diseases.
\end{abstract}

Key words Refugees, Feeding, Acculturation, Food and Nutrition Security, Nutritional Status.
Resumo As recentes crises e conflitos em países Africanos, no Oriente Médio e Américas têm originado migração forçada de populações e reacende a preocupação com os cuidados com a alimentação. O objetivo deste artigo é mapear na literatura científica as implicações da migração forçada sobre a alimentação e nutrição de refugiados. Scoping Review, com buscas nas bases de dados: bases de dados: PubMed Central, LILACS, SciElo, Science Direct e MEDLINE. Os idiomas de pesquisa foram: Inglês, Português e Espanhol, e ano de publicação compreendido entre 2013 e 2018. Obteve-se 173 artigos e após remoção dos duplicados e leitura integral, 26 artigos foram selecionados e submetidos à leitura critica por dois revisores independentes, resultando em 18 artigos selecionados. $\mathrm{Da}$ análise dos resultados dos artigos, emergiram as categorias: Iniquidade Alimentar; Adaptação Cultural e Nutrição; Doenças Emergentes e Estratégias de Promoção da Saúde Nutricional. A insegurança alimentar é consequência marcante da imigração internacional forçada, e se constitui um emergente problema de saúde pública global, pois concomitante aos crescentes deslocamentos populacionais também se ampliam a gama de doenças crônicas e nutricionais.

Palavras-chave Refugiados, Alimentação, Aculturação, Segurança Alimentar e Nutricional, Estado Nutricional. 


\section{Introduction}

Food is a basic need of the human being and is included in Article 25 of the Universal Declaration of Human Rights of $1948^{1}$. Feeding was already a concern in 1798, with Thomas Malthus's postulates regarding the supplanting of population growth in relation to production capacity. However, the rapid growth in global agricultural productivity has surpassed expectations and the production is able to feed the entire world population. Nonetheless, factors still contribute to the vulnerability of populations to hunger and food insecurity ${ }^{2}$.

The concept of Food Security was built over the years, and following the World Food Summit Declaration in 2002, it was reaffirmed "...respect for all human rights and fundamental freedoms..." ${ }^{3}$. However, the difficulties of measuring the state of food security have led to the development of the concept of the state of Food Insecurity as "a situation where people do not have access to sufficient quantities of safe and nutritious food and therefore do not consume the food they need to grow normally and lead an active and healthy life"4.

Recent conflicts in Africa, the Middle East and the Americas have led to the involuntary and forced displacement of populations. In 2017, the United Nations published the Global Trends Report, which indicates that by the end of 2016, 65.6 million people have been displaced worldwide due to persecution, conflict, violence or violations of human rights. This result represented an increase of 300,000 people over the previous year, the highest ever recorded ${ }^{5}$. This increase in the flow of population migration to other countries rekindles concern about the vulnerabilities to which these may be subject, such as food, access to services, education, work and income $e^{6}$. Thus, it is intended to map in the scientific literature the implications of forced migration on food and nutrition of refugees.

\section{Method}

Scoping Review is the method used in this study. Also called Scoping Study, it aims to map the main concepts that support a certain area of knowledge, examining the extent, scope and nature of the research, which leads to synthesize, propagate data and the identification of the research gaps ${ }^{7-10}$.

Thus, the research question was: "What are the implications of forced international migration on nourishment and nutrition of refugees?". And its formulation, according to the mnemonic $\mathrm{PICo}^{7}$, considered Population: refugees, Interest: forced international migration and implications on food, and the Context: health services and nongovernmental organizations? ${ }^{7}$.

The surveys were conducted in March and April 2018 in the following databases: PubMed Central (US National Institutes of Health), LILACS (Latin American and Caribbean Center for Health Sciences Information), SciElo (Scientific Electronic Library Online WEB OF SCIENCE), Science Direct and MEDLINE (Complete - US National Library of Medicine). The descriptors and synonyms were used after consulting the trilingual dictionary Descriptors in Health Sciences (DeCS) and MeSH (Medical Subject Headings), as shown in Table 1. The descriptors were combined to find scientific articles addressing aspects of nourishment and nutrition of refugees.

Original and review studies covering food and nutrition aspects of refugees were included. Study protocols, and studies that did not provide food or nutrition for refugees were excluded. The titles of articles without access were requested from the Library of the Faculdade de Medicina da Universidade Federal Fluminense.

Idioms used in the survey were: English, Portuguese and Spanish, with publication year from 2013 to 2018, a period of world humanitarian crisis surge in the Americas, the Middle East and African countries, with a significant increase in involuntary population migration.

The descriptors and their combinations used to construct the strategies were: "Strategies AND Refugees"; "Diet, food and Nutrition AND Refugees"; "Eating AND Refugees"; "Feeding Behavior AND Refugees"; "Strategies OR Diet, food and nutrition AND Refugees", and their correspondents in English language, Portuguese and Spanish, as presented in Table 1.

An instrument for data extraction was used to collect the following data from the studies: authors, year of publication, country where the study was conducted, target population, method, intervention and duration of intervention, and points related to scoping review, as: access to food, needs in food and nutrition, diseases related to the state of food and nutrition, coping strategies, aiming to synthesize the information. The present study was conducted by six independent reviewers who participated in the selection, analysis, and discussion of the selected articles. The thematic analysis of the articles selected resulted in the synthesis of the findings? 
Table 1. Descriptors used in search of studies in databases.

\begin{tabular}{|c|c|c|c|c|}
\hline \multicolumn{3}{|c|}{ Descriptors in Health Sciences (DeCS) } & \multirow[t]{2}{*}{$\begin{array}{l}\text { Medical Subject } \\
\text { Headings (Mesh) }\end{array}$} & \multirow[t]{2}{*}{ Key-words } \\
\hline Português & Espanhol & Inglês & & \\
\hline Refugiados & Refugiados & Refugees & Refugees & \\
\hline Alimentação & Alimentación & Feeding & Eating & $\begin{array}{l}\text { Diet, food and } \\
\text { Nutrition }\end{array}$ \\
\hline $\begin{array}{l}\text { Comportamento } \\
\text { alimentar }\end{array}$ & $\begin{array}{l}\text { Conducta } \\
\text { Alimentaria }\end{array}$ & Feeding behavior & Feeding behavior & \\
\hline Estratégias & Estrategias & Strategies & Adaptation & Coping strategies \\
\hline
\end{tabular}

Source: survey data, 2018.

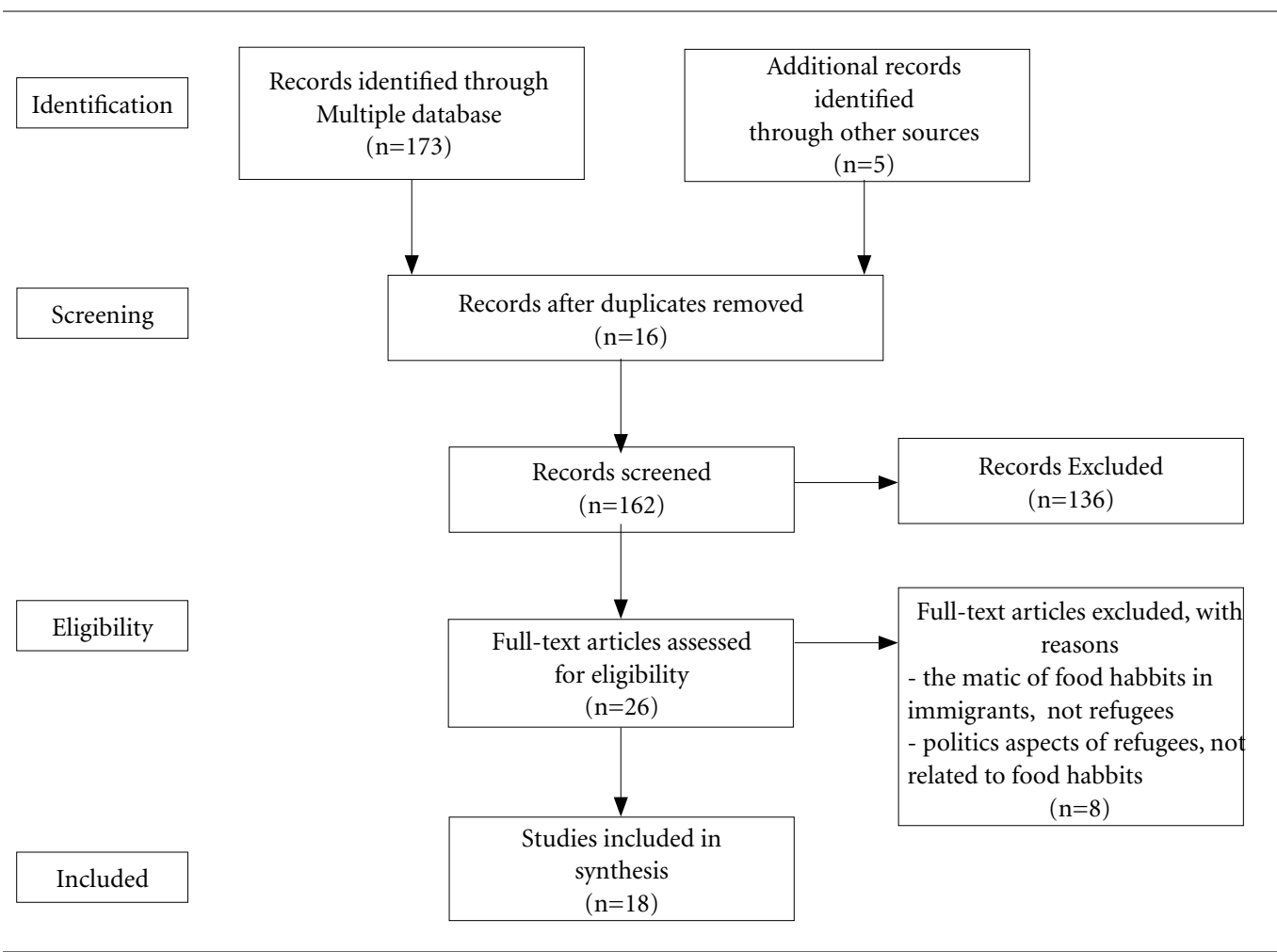

Figure 1. PRISMA, Scoping Review ${ }^{11}$.

\section{Results}

A total of 173 articles were found, of which 16 duplicates were withdrawn. After reading comprehensively, 26 articles were selected and submitted to critical reading by reviewers, resulting in 18 selected papers, which were assigned identification, as shown in Figure 1. From the selected were: 11 articles from Medline, 1 from Science Direct article, 1 from PubMed article, and 5 found through search in the references. From 18 selected studies, 13 were qualitative approach, 4 were quantitative approach articles, and one article was a mixed study. About the language, 17 articles were published in English and 1 article in Spanish. The food and nutrition of refugees was addressed under the prospect of settlement in refugee camps, in detention centers, and in destination countries where refuge was granted.

The studies were related to nutrition aspects from the point of view of the process of adaptation of refugees to the food environment, nutritional disorders, educational practices and feeding strategies in the refuge. The selected pa- 
pers were published from 2013 to 2017, in the following countries: seven studies conducted in the United States of America, followed by three studies conducted in Australia, one in Canada, one in Spain, one in Thailand, one in Algeria and one in Kenya ${ }^{12-28}$ (Table 2).

From the analysis of the results of the articles on the implications of forced international migration on food and nutrition of refugees, the following categories emerged: Food Inequity; Cultural Adaptation and Nutrition; Emerging Diseases; and Strategies for the Promotion of $\mathrm{Nu}$ tritional Health.

\section{Food Inequity}

This category covered 8 studies ${ }^{17,20-23,25,27,28}$ which presented aspects related to social, cultural, political and economic difficulties of access to food in refugee detention centers, refugee camps and in settlement destination countries.

The study A6 presents aspects of food insecurity in 700 families of Iraqi refugees living in Lebanon after a 10-year invasion of Iraq. The study reports rates of food insecurity of $80 \%$ of the participating families, with manifestations of deficient food diversity. The authors suggest that food insecurity is related to dissatisfaction with the country's policies towards refugee popula- tions, which limits access to work and income, thereby exacerbating food insecurity ${ }^{17}$.

The studies A9 and A12 presented aspects of food and nutrition for Palestinian refugees living in refugee camps in Lebanon. In the A9 study it was pointed out that of the 2,501 families participating in the study, 55\% had food insufficiency, $62 \%$ presented food insecurity, and also showed that households with residents with a disability (of known cause) had more reports of insufficient food, variation and severe food insecurity. The A12 study, conducted with 2,575 Palestinian refugee families, points to $41 \%$ (CI: 39-43) and 20\% (CI: 18-22) of Palestinian refugees experiencing moderate and severe food insecurity respectively. This study also shows the relation between food insecurity with poverty, unemployment, and some chronic illness or disability. Both studies report food insecurity in refugee camps in Lebanon, suggesting that local policies restricting employment, lack of education and provision of assistance to the population, informal work, marginalization of the refugee population and depletion of strategies of coping with reality are common in this scenario. In addition, the findings suggest that families of refugees with members with incapacitating physical disabilities are at greater risk of food shortages, and consequently food insecurity. Although the studies

Table 2. Characteristic of studies

\begin{tabular}{llll}
\hline \multicolumn{1}{c}{ Identification } & \multicolumn{1}{c}{ Autors } & $\begin{array}{c}\text { Year } \\
\text { (Publication) }\end{array}$ & \multicolumn{1}{c}{$\begin{array}{c}\text { Country Where The Study Was } \\
\text { Conducted }\end{array}$} \\
\hline A1 & Vatanparast H, & 2013 & Canada \\
A2 & Dharod J M & 2013 & United States of America \\
A3 & Gold A & 2014 & United States of America \\
A4 & Bhatta M P & 2014 & United States of America \\
A5 & Pour M S & 2014 & Australia \\
A6 & Ghattas H & 2014 & Lebanon \\
A7 & Tiedje K & 2014 & United States of America \\
A8 & Careyva B & 2015 & United States of America \\
A9 & Ghattas H & 2015 & Lebanon \\
A10 & Mckay FH & 2015 & Australia \\
A11 & Gichunge C & 2016 & Australia \\
A12 & Salti N & 2016 & Lebanon \\
A13 & Dawson-Hahn EE & 2016 & United States of America \\
A14 & Arroyo-Izaga M & 2016 & Spain \\
A15 & Wang Y & 2016 & United States of America \\
A16 & Stuetz W. & 2016 & Thailand \\
A17 & Morseth M S & 2017 & Algeria \\
A18 & Style S & 2017 & Kenya \\
\hline S & & &
\end{tabular}


point to the existence of humanitarian assistance, it also points out that this is insufficient to address barriers to food access ${ }^{20,23}$.

Studies A14 and A17 present food and nutrition aspects of Saharan refugees living in refugee camps in Algeria. Study A14 presents the dietary habits of a group of Saharauis refugee women who were residents of the Tindouf Field in Algeria prior to their migration to the destination country, where the participants reported the scarcity and low consumption of fresh food and the poor variety of food available. Study A17 presented the relationship between socioeconomic status and food diversity of Saharan refugees residing in five refugee camps in Algeria, and points out that low economic status was associated with low food diversity. Despite receiving food rations donated by humanitarian agencies, some refugees are able to practice farming and gardening to obtain fresh food as an alternative to prevent food shortages, even though limited by the climatic conditions as well as food resources and water availability. Humanitarian aid helps with primary needs but, as the study points out, food shortages and lack of purchasing power contribute to food insecurity 25,28 .

In study A16, it points out the need of supplementation of minerals, such as iron, in refugee camps in Thailand and the consumption reduction of traditionally cultural foods such as betel nut, a characteristic seed of Asia. In addition, it is important to point out that the participants of the study were assisted by humanitarian food donation programs, and some families still reported the raising of animals such as poultry, pigs and goats, as a way to obtain food diversity ${ }^{27}$.

Study A10 presented the situation of asylum seekers residing in detention centers in Melbourne, Australia. It pointed out that while waiting for determination of refugee status, temporary support is offered with English language classes, health care and food supplies. However, $90 \%$ of the participants interviewed showed that they were food insecure due to lack of access to work and income, some showed that they were hungry, with consequent weight loss and emergence of emotional problems. These findings points out that, even with government assistance, there is inadequate and insufficient food supply, and policies that restrict work makes access to income impossible ${ }^{21}$.

In A11, the situation of access to traditional food of African refugees residing in Australia is pointed out. The results showed that age, employment, cultivation of vegetables and access to supermarkets in the neighborhood were factors that allowed access to traditional foods of the African culture. It is also pointed out that the language and the fact of having to seek access to food in other neighborhoods are impeding factors in accessing their food of preference ${ }^{22}$.

\section{Cultural Adaptation and Nutrition}

This category encompassed 9 studies ${ }^{12,13,15,17-19,22,24,26}$ which provided perspectives on feeding and adaptation of the refugee population to new food crops in camps and settlements. Resettlement in the refugee country presents new realities to refugee families, such as exposure to new eating habits, acquisition of food of low cost and nutritional quality, new habits of living, practice of sedentary activities such as watching television, playing video games and using computers.

In study A1, the authors point to the low consumption of food sources of calcium and vitamin D by refugee children in Canada, representing poor nutrition quality, in addition, it points out that vitamin $\mathrm{D}$ depletion is common in areas of high latitude, especially during the winter months ${ }^{12}$.

In $\mathrm{A} 4$ the authors demonstrate the process of western habits incorporation in a population of refugee women from Bhutan residing in Ohio, United States of America, as the introduction of meats, soft drinks (soft drinks and industrialized juices) and sedentarism. Although the Nepal-Bhutan culture is characterized by high carbohydrate consumption, an increase in this consumption associated with post-settlement sedentary lifestyle predisposes this population to cardio-metabolic diseases. Nonetheless, in study A7, conducted with 11 to 65 -year-old refugees residing in the USA, it is demonstrated that refugees are knowledgeable about healthy and unhealthy eating patterns. But they tend to adapt this knowledge in the new country of residence. It also points out that acculturation is associated with changes in dietary pattern, to a less healthy pattern $^{15,18}$.

The study A6 indicates dietary habits reported by Iraqi refugees in Lebanon, showing that there is poor food diversity in the new habits in the settlement country, with low consumption of fruits and meat, and high consumption of cereals and fats due to economic barriers. Study A8, however, points to changes in the body composition of refugees from Southeast Asia, Africa and the Middle East, associated with the process of 
acculturation, changes in physical activity patterns, past and present food insecurity, and environmental factors such as provision of fresh food appropriate to the culture of that population ${ }^{17,19}$.

The A15 study, a review article, points out that the food pattern of refugees is variable between groups and that changes in post-settlement food behavior differ according to age and socioeconomic status. However, it points out that refugees from South Asia are more likely to maintain dietary habits, according to their traditions ${ }^{17}$.

In Study A7, the authors point to inadequate cholesterol levels in young Afghan refugees settled in Australia as a reflection of malnutrition conditions in early life, as well as the food transition to a high-fat diet and the sedentary style of life ${ }^{19}$. In study A11, conducted in Queensland, Australia, it was evidenced that African refugees preferred the consumption of vegetables and other foods that refer to the culture in their country of origin. However, in some nuclei, the children indicated preferences for processed foods available in their new environment ${ }^{23}$. Study A6 shows the habits of Saharauis refugee women post-resettlement in Spain, showing the balance of macronutrient consumption in relation to the habits presented in the refugee camp, but with low consumption of monounsaturated fatty acids and in addition to the increase in the consumption of sweets, cereals, and lower consumption of vegetables ${ }^{18}$. The study suggests that the inadequacy in the consumption in relation to the Mediterranean dietary habits is related to the lack of knowledge, the pressure in the publicity and the influence of the Western food model, that is, adaptation to new food.

\section{Emerging diseases}

This category covered 8 studies ${ }^{12,13,15,16,19,24,27,28}$ that presented scenarios of emerging diseases, such as food deficiencies and nutritional disorders in refugee populations.

A high prevalence of overweight $(65 \%)$ and abdominal obesity $(69 \%)$ in a population sample of 120 participating Bhutanese refugees residing in the USA were found in study A4. In study A8, the authors point to changes in the body mass index of refugees from Southeast Asia, Africa and the Middle East, also residing in the USA, during the period of the first 18 months of settlement, with a transition from adequate to overweight in a relatively short time ${ }^{15}$. Likewise, study A2 presents the relationship between inadequate caloric intake and body weight gain in Somali refugees living in the USA, evidencing overweight and obesity in more than two thirds of the studied population, also exposes that overweight and obesity are indicators of health normalized in the West and suggests a strong relation of these nutritional disorders with the culture of the country of origin, where a bulky body is synonymous with prosperity and preparation to scarcity, such as in dry seasons and low food productivity ${ }^{13}$.

Study A16 showed that the high prevalence of anemia and iron deficiency in pregnant women living in Campo Maele, and even after the use of supplementation strategies. It suggests that the persistence of deficiencies may be related to helminth infection or deficiencies of other micronutrients, in camps where hygiene conditions are precarious and several families share the same sanitary, and considering the extremely restrictive feeding, being in charge of the refugees to purchase vegetables and fruits, that is to say, depending on purchasing power ${ }^{27}$. In A18 the effectiveness of introducing a small lipid-based supplement to reduce anemia in refugee children from 0 to 59 months of age, not altering the state of dwarfism or acute malnutrition of this population, living in camps in the Horn of Africa. Noting that despite the efforts with fortification and supplementation programs, in addition to food basket donations, to alleviate food and nutritional deficits in refugee camps, malnutrition and macro and micronutrient deficiencies are still perennial ${ }^{29}$.

Resettlement in a new country is not a sign that deficiencies and food shortages remain in the past. Studies A1, A5 and A13 pointed to malnutrition, nutritional deficiencies in refugees in different age groups. Among the main deficiencies pointed out are: vitamin D deficiency and vitamin B12 deficiency. Regarding the forms of malnutrition, the studies indicate: overweight, dyslipidemia, delayed growth, low weight, and overweight and obesity ${ }^{12,16,24}$.

Study A1 reported data from the Canadian Health Indicators Survey conducted on 5,500 immigrant and nonimmigrant Canadian children, where alarming rates of vitamin $\mathrm{D}$ deficiency were found, especially in $29 \%$ of 7 to 11 -year-old refugee children, with less than 3 years of residence in Canada, particularly female children. The study suggests that this deficiency may be due to the low consumption of vitamin D and calcium sources, such as milk and milk products, as well as depletion during periods of long winter and inadequate repletion during the mild climate in the summer ${ }^{12}$. 
Study A5 pointed to micronutrient deficiency in Afghan refugees residing in rural Australia. In the study conducted in 92 refugee patients who sought health care, vitamin $D$ deficiency was found in $50 \%$ of them, vitamin B12 deficiency in $18.4 \%$, abnormal cholesterol levels, approximately $1 / 4$ of the study participants had dyslipidemia, and $30 \%$ were obese. The authors suggest that nutritional deficiencies and malnutrition are related to food insecurity in the country of origin, inadequate nutrition during the period they were applying for asylum and remained in detention centers in Australia (approximately 12 months to 3 years), low consumption of products of animal origin, and the food transition to which they are subject after settlement in Australia ${ }^{15}$.

The A13 study, conducted with the participation of 982 refugee children, showed the prevalence of malnutrition in $44.9 \%$ of refugee children aged 0-10 years residing in the USA, Washington State. Among the main malnutrition states found were: $17.3 \%$ with low weight for age, $20.1 \%$ had growth retardation, for age, $7.6 \%$ were overweight and $5.9 \%$ were obese. The findings are related to the medical examinations performed immediately after the migration and demonstrate that at least half of the children presented some nutritional compromise. It also indicates that children of Iraq origin had a higher prevalence of overweight $(9.8 \%)$ and obesity $(9,4 \%)$ when compared to those of Somalia and Burma origins. The study evidenced malnutrition from anthropometric developmental data among children on arrival in the country of refuge, pointing to the highest risk among children 5-10 years of age, and varying according to country of origin ${ }^{23}$.

\section{Nutrition and Health Promotion Strategies}

This category covered the 3 studies ${ }^{13,14,18}$ which presented strategies for promoting nutritional health practices in refugee populations in camps and in resettlement in the destination country of refuge.

A3 points to teaching strategies on food security in US settled refugees, aiming to broaden refugees' knowledge about food practices through the Food Security Map tool. While demonstrating the effectiveness of this new tool, compared to the knowledge taught in traditional cooking classes, it has also proved to be a low cost alternative, simple applicability and convenience for people learning English ${ }^{13}$.

Conditions in refugee camps are precarious regarding the provision of food and health ser- vices, thus, studies A14 and A18 present strategies for fortification and food supplementation for pregnant women and children, respectively. Study A14 results in the investigation of food habits in refugees in Spain from Campo Tindouf (Algeria), the design of a nutrition education program for refugees still living in the countryside, by training refugee women who participate in community leaderships, with the aim of propagating knowledge about: food and its composition, energy and nutrient needs, healthy eating and feeding in special situations (gestation, children, elderly), food preparation and hygiene practices $^{24}$. In A18, effectiveness of a food supplement to reduce anemia and dwarfism in refugee children in Africa, an attempt to circumvent present and contributing health problems to the delay in child development ${ }^{28}$.

\section{Discussion}

The growing number of people affected by forced displacement highlights a public health concern in countries that provide shelter to these populations, especially in terms of food, nutrition and health promotion strategies, such as the promotion of nutritional education and prevention of hunger, malnutrition and overweight/obesity. Of particular note is the large number of selected articles published in the United States, Australia and Lebanon, which are notable for the high demands for asylum applications and diversified refugee reception policies.

However, food insecurity is still constant, while refugees living in camps and detention centers are expanding, especially in countries that have restrictive policies on work, income and refugee education, with consequent poverty, lack access to income, poor hygiene structures and a greater propensity for chronic diseases, in some cases incapacitating diseases ${ }^{30}$, making these populations mainly dependent on humanitarian aid. In some countries, such as Lebanon, refugees do not have the right to work, public health and education services, and thus clusters of refugees are waiting for donations since the government cannot provide more efforts ${ }^{30-33}$. In other countries such as Algeria, refugees depends exclusively on humanitarian aid, seasonal food and vegetable donations, due to extreme climatic conditions, as refugee camps are concentrated in the midst of the desert, and even with the existence of some of these markets, refugees do not have purchasing power, since financial resources are scarce ${ }^{32}$. 
Restrictive conditions can also be observed in developed countries, such as Australia, where access to work is limited to the type of visa granted, and the waiting for the visa that enables access to work is often delayed, making these populations susceptible to difficulties in accessing balanced food within detention centers, which compromises daily needs, since all food comes from the assistance services of those centers ${ }^{33}$.

A consequence of forced migration is the process of acculturation, that is, adaptation to new food habits and the food environment and living habits of the country of refuge. This transition of habits and customs, however, is evidenced as a factor that can provide food insecurity, by propagating a higher consumption of processed foods, and lower consumption of fresh and nutritious foods. Despite the nutritional value of vegetables, in some countries, the high cost of these foods may lead to the consumption of less nutritious foods, and in consequence the higher consumption of processed food that is economically more accessible than vegetables and fruits ${ }^{34,35}$. Moreover, it is important to note that in the process of acculturation, some habits and costumes of the country of tradition may be forgotten, also by the lack of traditional food and difficult to access in the country of settlement. In addition to new eating habits, a sedentary lifestyle also seems to contribute to overweight, also caused by malnutrition $^{36}$.

Other consequences of forced displacement are nutritional deficiencies and post-settlement malnutrition. The studies are characterized by greater attention to the deficiencies in children and pregnant women population. However, there is a mass population that is also vulnerable to the nutrition deficiencies found in the settlement due to the eating behavior. The most frequent deficiencies found in the studies are those of vitamin $\mathrm{D}$, vitamin $\mathrm{B} 12$ and iron ${ }^{37,38}$. All associated with diseases for the low consumption of food sources of these nutrients in post-settlement refugees. Thus, nutritional status such as dyslipidemia, overweight and obesity, show the emergence of chronic non-degenerative diseases, as a result of consumption of low-cost and low nutritional value foods, instead of food such as fruits and vegetables, as a coping strategy to not suffer from hunger, and since these foods are more accessible $e^{39,40}$.

Some countries, where refugee food insecurity are already echoing in public health priorities, have begun strategies for reducing food insecurity, supplementation, food fortification, or new food and nutrition education tools, like cooking classes and food workshops for refugees ${ }^{41}$. Malnutrition is closely related to the onset of chronic diseases, and health promotion and prevention tools are indispensable for use with vulnerable populations. In some cases, such as in refugee camps, training refugees to be information multipliers is a step that can provide knowledge without estrangement in food choices, food use, preservation, preparation and health ${ }^{42}$. Likewise, fortification and supplementation in refugee camps are strategies, that are more focused on the most predisposing populations to risk: pregnant women, the elderly and children, but they are not yet effective in reaching the entire population and eradicating food insecurity status referred to nutrient absorption, still needing more improves ${ }^{43}$.

Food security is based on four dimensions: food availability, access to food, use of food and stability. The availability of food means having enough food available. Access to food means physical, social and economic access. The use of food, however, refers to food selection, preservation and preparation as well as nutrient absorption. And stability is related to the permanent and uninterrupted access to food. Each dimension takes into account the need to reach a safe, adequate and necessary foo ${ }^{44}$. In addition, food security also includes respect for diversity and cultural foods. The condition of food insecurity occurs when one of these dimensions ceases to occur, and subjects the population to nutritional risks, such as refugees who do not have permanent access to food, or who do not have physical or economic access, or when food is prepared under inappropriate conditions in refugee households or camps, where resources are scarce ${ }^{30-39}$.

\section{Conclusion}

Food insecurity is the main consequence of forced international migration for refugee nourishment, and constitutes an emerging global public health problem, along with increasing population displacements, the range of chronic and nutritional diseases is also increasing. More studies are needed to expand strategies for prevention and health promotion to refugee populations, as well as the review of policies for the reception of refugees and asylum seekers, considering the process of adaptation to the habits, customs of the country of resettlement and strategies in nutritional education, also valuing the respect to tradition and practices of food culture from the country of origin. 


\section{Collaborations}

JVV Guerra, VH Alves, L Rachedi, AV Pereira, MV Santos, MBLR Branco, MC Schveitzer and BF Carvalho: conceived and designed the analysis, collected the data, performed the analysis, wrote the paper and critical revision.

\section{References}

1. Melo ZM, Brum MF, Silva AMCS, Meira DD, Sales MDC. Marcos referenciais na trajetória da segurança alimentar e nutricional: panorama mundial e nacional. Pensar Acadêmico 2017; 15(1):95-108.

2. Nascimento AL, Andrade SLLS. Segurança alimentar e nutricional: pressupostos para uma nova cidadania. Cienc Cult 2010; 62(4):34-38.

3. Food and Agriculture Organization of the United Nations (FAO). World Food Summit: Rome Declaration on World Food Security and World Food Summit Plan Action. 1996 Nov 13-17; Roma, Itália.

4. Food and Agriculture Organization of the United Nations (FAO). Report of the World Food Summit five years after. 2002 Jun 10-13; Roma, Itália.

5. Agência da ONU para refugiados (ACNUR). Global trends: forced displacement in 2016. Genebra: UNHCR; 2017.

6. Santos JES, Calsing RA, Silva VL. Refugiados no Brasil: estamos preparados para a proteção humanitária daquelas pessoas? NOMOS: Revista do Programa de Pós-Graduação em Direito da UFC 2017; 37(2):187214.

7. Peters MDJ, Godfrey C, McInerney P, Baldini Soares C, Khalil H, Parker D. Chapter 11: Scoping Reviews. In: Aromataris E, Munn Z, editores. Joanna Briggs Institute Reviewer's Manual. The Joanna Briggs Institute; 2017.

8. Principais itens para relatar Revisões sistemáticas e Meta-análises: A recomendação PRISMA. Epidemiol Serv Saúde 2015; 24(2):335-342.

9. Brasil. Ministério da Saúde (MS). Secretaria de Ciência, Tecnologia e Insumos Estratégicos. Departamento de Ciência e Tecnologia. Diretrizes metodológicas: elaboração de revisão sistemática e metanálise de ensaios clínicos randomizados. Brasília: MS; 2012 (Série A: Normas e Manuais Técnicos).

10. Menezes SSC, Corrêa CG, Silva RCG, Cruz DAML. Clinical reasoning in undergraduate nursing education: a scoping review. Rev Esc Enferm USP 2015; 49(6):1037-1044.

11. Tricco AC, Lillie E, Zarin W, O’Brien KK, Colquhoun H, Levac D, Moher D, Peters MDJ, Horsley T, Weeks L, Hempel S, Akl EA, Chang C, McGowan J, Stewart L, Hartling L, Aldcroft A, Wilson MG, Garritty C, Lewin S, Godfrey CM, Macdonald MT, Langlois EV, Soares-Weiser K, Moriarty J, Clifford T, Tunçalp Ö, Straus SE. PRISMA Extension for Scoping Reviews (PRISMA-ScR): Checklist and Explanation. Ann Intern Med 2018; 169(7):467-473.
12. Vatanparast H, Nisbet C, Gushulak B. Vitamin D insufficiency and bone mineral status in a population of newcomer children in Canada. Nutrients 2013; 5(5):1561-1572. [included in the revision]

13. Dharod JM, Croom JE, Sady CG. Food Insecurity: Its Relationship to Dietary Intake and Body Weight among Somali Refugee Women in the United States. $J$ Nutr Educ Behav 2013; 45(1):47-53. [included in the revision]

14. Gold A, Yu N, Buro B, Garden-Robinson J. Discussion Map and Cooking Classes: testing the effectiveness of teaching food safety to immigrants and refugees. J Nutr Educ Behav 2014; 46(6):547-553. [included in the revision]

15. Bhatta MP, Assad L, Shakya S. Socio-Demographic and dietary factors associated with excess body weight and abdominal obesity among resettled bhutanese refugee women in Northeast Ohio, United States. Int J Environ Res Public Health 2014; 11(7):6639-6652. [included in the revision]

16. Pour MS, Kumble S, Haniet S, Biggs BA. Prevalence of dyslipidaemia and micronutrient deficiencies among newly arrived Afghan refugees in rural Australia: a cross-sectional study. BMC Public Health 2014; 14:896. [included in the revision]

17. Tiedje K, Wieland ML, Meiers SJ, Mohamed AA, Formea CM, Ridgeway JL, Asiedu GB, Boyum G, Weis JA, Nigon JA, Patten C, Sia IG. A focus group study of healthy eating knowledge, practices, and barriers among adult and adolescent immigrants and refugees in the United States. Int J Behav Nutr Phys Act 2014; 11:63. [included in the revision]

18. Ghattas H, Sassine AJ, Seyfert K, Nord M, Sahyoun NR. Food insecurity among Iraqi refugees living in Lebanon, 10 years after the invasion of Iraq: data from a household survey. Br J Nutr 2014; 112(1):70-79. [included in the revision]

19. Careyva B, LaNoue M, Bangura M, Paz A, Gee A, Patel N, Mills G. The Effect of living in the United States on body mass index in refugee patients. J Health Care Poor Underserved 2015; 26(2):421-430. [included in the revision]

20. Ghattas H, Sassine AJ, Seyfert K, Nord M, Sahyoun NR. Prevalence and correlates of food insecurity among palestinian refugees in Lebanon: data from a household survey. PloS One 2015; 10(6):e0130724. [included in the revision] 
21. Mckay FH, Dunn M. Food security among asylum seekers in Melbourne. Aust N Z J Public Health 2015; 39(4):344-349. [included in the revision]

22. Gichunge C, Somerset S, Harris N. Using a household food inventory to assess the availability of traditional vegetables among resettled African refugees. Int $J$ Environ Res Public Health 2016; 13:137. [included in the revision]

23. Salti N, Ghattas H. Food insufficiency and food insecurity as risk factors for physical disability among Palestinian refugees in Lebanon: Evidence from an observational study. Disabil Health J 2016; 9(4):655662. [included in the revision]

24. Dawson-Hahn EE, Pak-Gorstein S, Hoopes AJ, Matheson J. Comparison of the Nutritional Status of Overseas refugee children with low income children in Washington State. PloS One 2016; 11(1):e0147854. [included in the revision]

25. Arroyo-Izaga M, Muñoz VA, Demont G. Diseño de un programa de educación nutricional destinado a mujeres saharauis residentes en los campamentos de Tinduf (Argelia). Nutr Hosp 2016; 33(1):91-97. [included in the revision]

26. Y, Min J, Harris K, Khuri J, Anderson LM. A systematic examination of food intake and adaptation to the food environment by refugees settles in the United States. Adv Nutr 2016; 7(6):1066-1079. [included in the revision]

27. Stuetz W, Carrara VI, Mc Gready R, Lee SJ, Sriprawat K, Po B, Hanbookunupakarn B, Grune T, Biesalski HK, Nosten FR. Impact of Food Rations and Supplements on micronutrient status by trimester of pregnancy: cross-sectional studies in the Malae refugee Camp in Thailand. Nutrients 2016; 8:66. [included in the revision]

28. Morseth MS, Grewal NK, Kaasa IS, Hatloy A, Barikmo I, Henjum S. Dietary diversity is related to socioeconomic status among adult sahrawi refugees living in Algeria. BMC Public Health 2017; 17:621. [included in the revision]

29. Style S, Tondeur M, Grijalva-Eternod C, Pringle J, Kassim I, Wilkinson C, Oman A, Dolan C, Spiegel P, Seal A. Assessment of the effectiveness of small quantity lipid-based nutrient supplement on reducing anaemia and stunting in refugee populations in the Horn of Africa: secondary data analysis. PloS One 2017; 12(6):e0177556. [included in the revision]

30. Parkinson SE, Behrouzan O. Negotiating health and life: Syrian refugees and the politics of access in Lebanon. Soc Sci Med 2015; 146:324-331.

31. UN High Commissioner for Refugees (UNHCR), UN Children's Fund (UNICEF), World Food Programme (WFP). Vulnerability assessment of Syrian refugees in Lebanon 2016. Genebra; 2017.

32. Cortés MJ, Sotomayor MEM. La Exclusión Social de las personas con discapacidad en situaciones de pobreza: el caso de los campamentos saharauis de Argelia. Index Enferm 2016; 25(3):180-184.

33. Lawlis T, Islam W, Upton P. Achieving the four dimensions of food security for resettled refugees in Australia: a systematic review. Nutr Diet 2018; 75(2):182192.
34. Ross WL, Gallego-Pérez DF, Lartey A, Sandow A, Pérez-Escamilla R, Hromi-Fiedler A. Dietary patterns in Liberian refugees in Buduburam, Ghana. Matern Child Nutr 2017; 13(4):e12401.

35. Anderson L, Hadzibegovic DS, Moseley JM, Sellen DW. Household Food Insecurity Shows Associations with Food Intake, Social Support Utilization and Dietary Change among Refugee Adult Caregivers Resettled in the United States. Ecol Food Nutr 2014; 53(3):312-332.

36. Bhatta MP, Shakya S, Assad L, Zullo MD. Chronic Disease Burden Among Bhutanese Refugee Women Aged 18-65 Years Resettled in Northeast Ohio, United States, 2008-2011. J Immigr Minor Health 2015; 17(4):1169-1176.

37. Moffat T, Sellen D, Wilson W, Anderson L, Chadwick $S$, Amassa S. Comparison of infant vitamin D supplement use among canadian-born, immigrant and refugee mothers. J Transcult Nurs 2014; 26(3):261-269.

38. Wolfgang S, Carrara VI, McGready R, Lee SJ, Erhardt JG, Breuer J, Biesalski HK, Nosten FH. Micronutrient status in lactating mothers before and after introduction of fortified flour: cross-sectional surveys in Maela refugee camp. Eur J Nutr 2012; 51(4):425-434.

39. Nidzvetska S, Rodriguez-Llanes JM, Aujoulat I, Cuesta JG, Tappis H, Loenhout JAFV, Guha-Sapir D. Maternal and Child Health of internally displaced persons in Ukraine: a qualitative study. In J Environ Res Public Health 2017; 14(1):54.

40. Mishori R, Aleinikoff S, Davis D. Primary care for refugees: challenges and opportunities. Am Fam Physician 2015; 96(2):112-120.

41. Blount AJ, Acquaye HE. Promoting wellness in refugee populations. Journal of Counseling \& Development 2018; 96:461-472.

42. Korfmacher KS, George V. Educating refugees to improve their home environmental health. J Public health Manag Pract 2012; 18(5):469-473.

43. Tondeur MC, Salse NU, Wilkinson C, Spiegel P, Seal AJ. Rapid acceptability and adherence testing of a lipid-based nutrient supplement and a micronutrient powder among refugee children and pregnant and lactating women in Algeria. Public Health Nutr 2016; 19(10):1852-1861.

44. Vasconcellos ABPA, Moura LBA. Segurança alimentar e nutricional: uma análise da situação da descentralização de sua política pública nacional. Cad Saude Publica 2018; 34(2):e00206816.

Artigo apresentado em 30/10/2018

Aprovado em 12/07/2019

Versão final apresentada em 12/08/2019 